\title{
Interactive comment on "Charactersing
} spatio-temporal variability in seasonal snow cover at a regional scale from MODIS data: The Clutha Catchment, New Zealand" by Todd A. N. Redpath et al.

Todd A. N. Redpath et al.

todd.redpath@otago.ac.nz

Received and published: 18 June 2019

Please see supplement.

Please also note the supplement to this comment:

https://www.hydrol-earth-syst-sci-discuss.net/hess-2019-30/hess-2019-30-AC3- 
30, 2019.

HESSD

Interactive

comment

Printer-friendly version

Discussion paper

(c) (i) 